\title{
Experimental Investigation of Critical Heat Flux During Impact of a Droplet onto Hot Horizontal Surface
}

\author{
N. A. Rosman ${ }^{1}$, S. Illias ${ }^{1}$, S. Hussain ${ }^{1}$, A. I. M. Shaiful ${ }^{1}$, M. H. Ani ${ }^{2}$ \\ ${ }^{1}$ School of Manufacturing Engineering, Universiti Malaysia Perlis, 02600 Arau Perlis Malaysia. \\ ${ }^{2}$ Department of Manufacturing and Materials, Kulliyyah of Engineering, International Islamic University \\ Malaysia, PO Box 10, 50728 Kuala Lumpur, Malaysia
}

\begin{abstract}
The purpose of this research is to investigate the Critical Heat Flux (CHF) and its relationship with thermal inertia during impact of a droplet on hot horizontal surface. In the study, three (3) different types of material were used which were Aluminum, Brass and Stainless Steel (304). The materials dimension were $50.0 \mathrm{~mm}$ in diameter and $30.0 \mathrm{~mm}$ in height. The materials were polished until they became a mirror polished surface. Ethanol was used as the test liquid. The droplet diameter was approximately $3.528 \mathrm{~mm}$. The impact height was approximately $65.0 \mathrm{~mm}$ corresponding to impact velocity of $1.129 \mathrm{~m} / \mathrm{s}$. The evaporation lifetime was measured in seconds by using a digital stopwatch. As a result, it was observed that the CHF occurred at the surface temperatures of 105,120 and $160^{\circ} \mathrm{C}$ for aluminum, brass and stainless steel, respectively. It was also observed that all $\mathrm{CHF}$ data showed an evaporation lifetime below $1 \mathrm{sec}$ order which is similar with other literatures.
\end{abstract}

Key words: Droplet impact, Horizontal surface, Evaporation lifetime, Critical Heat Flux,

\section{INTRODUCTION}

Basically, boiling mode can be divided into three (3) main categories which are the nucleate [1-2], transition [3-4] and film boiling [5-7] regimes. Among these three, nucleate boiling is widely used in energy industries. During an evaporation process [8-10], droplets or liquid will release an amount of pressure that can be used to spin turbines in order to generate electricity. Therefore, boiling can be considered as one of the most important elements for energy industries around the world. The simplest method that can be used to study this complicated phenomena is by using a droplet impact experiment. Droplet impact experiment is widely used in boiling heat transfer to study the relation between contact angle and surface roughness [11], droplet characteristics on dry and wetted surfaces [12], steel making process, energy efficiency [13] and many others which are closely related to thermal engineering application. The new findings of this experimental work can enhance the capability of a material to absorb or release heat in thermal application industries. On top of that, it also gives benefits to power generation industry and power plant facilities especially cooling and thermal protection systems. There are a few scientists and researchers who have devoted their commitment and curiosity to study the complicated phenomena of droplet impact and boiling process. For instance, Fujimoto et al. [14] developed an experimental understanding of the collision and contact behavior of aqueous polymer solution droplets with a hot substrate. A transparent sapphire prism was used to observe the transient contact behavior of droplets with a hot solid. In the experimental work, the surface temperature varied from 300 to $600{ }^{\circ} \mathrm{C}$. As a result, they found that the Weber number considerably influenced the deformation behavior of droplets. For $\mathrm{We} \approx 100$, the droplet impacted onto the solid substrate, spread, and split into pieces because of the bursting of boiling bubbles at the free surface and/or large impact inertia. For We $\approx 30$ and high temperatures of the solid substrate, the droplet rebounded off the solid. Zhao et al. [15] experimentally investigated a droplet impact on porous surface using a wide range of Weber numbers and surface temperatures. They found that neither the existing capillary regime nor viscous regime identified for droplet impacts on impermeable surfaces (or a combination of these regimes) could describe $\beta_{\max }$ for droplet impact on a porous surface over a wide range of We. Other researchers such as Illias et al. [16-21], Rosman et al. [22], Mitsutake et al. [23], Tsuboyama et al. [24] and Hasan et al. [25-26] also conducted a few experimental works regarding droplet impact research in order to improve the understanding regarding the relationship between droplet impact and hot surfaces.

In this paper, we focus our investigation in finding the Critical Heat Flux (CHF) by using three (3) different types of material. Aluminum, brass and stainless steel (304) have been chosen as the test materials. All the CHF results were compared with thermal inertia. Meanwhile, ethanol which has a low boiling point of $78^{\circ} \mathrm{C}$ was chosen as the test liquid. The droplet diameter was approximately $3.528 \mathrm{~mm}$. The impact height was set to be around $65.0 \mathrm{~mm}$ corresponding to an impact velocity of $1.129 \mathrm{~m} / \mathrm{s}$. As a result, it was found that $\mathrm{CHF}$ occurred on all selected materials. For aluminum, brass and stainless steel, the CHF was 105,120 and $160{ }^{\circ} \mathrm{C}$, respectively. Furthermore, it was found that materials with low thermal inertia, $\beta$ will have a much higher CHF. 


\section{EXPERIMENTAL APPARATUS}

Figure 1 shows the schematic diagram of the experimental apparatus. It consists of a hot plate, test material, retorts stand, manual droplet dispenser and temperature measuring device. Three different types of material were selected which were aluminum, brass and stainless steel. The dimensions of the test surface were $50.0 \mathrm{~mm}$ in diameter and $30.0 \mathrm{~mm}$ in height. The surface material was polished until it became a mirror polished surface. On top of that, the selection of this material was based on their thermal inertia or thermal properties, $\beta$. The thermal properties, $\beta=\left(\rho C_{p} k\right)^{1 / 2}$ is an important parameter in boiling heat transfer studies. During the impact test, the material was directly heated using a digital hot plate. This digital hot plate has very high accuracy capabilities in maintaining the temperature fluctuation. The droplet dispenser was put on top of the hot plate and the droplet dispenser was attached to a retort stand. The droplet dispenser can be moved forward and backwards in order to minimize the radiation effect from the hot plate. It was only when the drop test was conducted that the droplet dispenser was placed at the drop impact point (drop zone). The drop impact point was set to be at the center of the surface material. The falling height of the droplet was set to around $65.0 \mathrm{~mm}$ corresponding to impact velocity of $1.129 \mathrm{~m} / \mathrm{s}$. This impact height was in the range that the droplets will not disintegrate with collision energy during the impact. In other words, the droplet will not splash away during the initial impact test at room temperature. The surface temperature ranged from a low temperature of $70^{\circ} \mathrm{C}$ up to a high temperature of $200^{\circ} \mathrm{C}$. In order to measure the surface temperature, two (2) tiny holes were dug using conventional CNC milling on top of the test material. Then, two thermocouples type $\mathrm{K}$ were inserted carefully into the tiny holes. During experimental work, the temperature difference between both thermocouples was below $1{ }^{\circ} \mathrm{C}$. During the drop test, the evaporation lifetime was recorded using a digital stop watch. As a backup, video smartphone also was used to record the evaporation process. The data was recorded for six (6) times and the average reading was also calculated. The experimental apparatus is quite similar with our previous report [20-22].

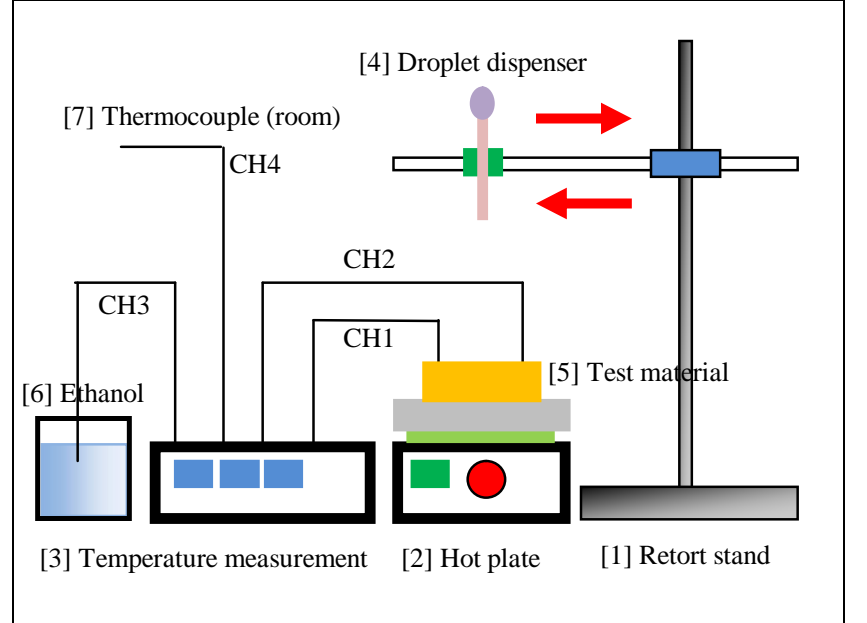

Figure 1 : Schematic diagram of the experimental apparatus

\subsection{EXPERIMENTAL CONDITIONS}

The experimental conditions are tabulated in Table 1 for easy understanding. The diameter of the droplet was calculated based on the droplet volume formula and theoretical calculation [22]. Instead of using distilled water, we used ethanol liquid in the experimental work. Due to the low boiling point and liquid properties of ethanol, it was chosen as a test liquid.

Table 1: Experimental conditions

\begin{tabular}{l|l}
\hline Diameter of ethanol droplet, $\mathrm{D}_{0}(\mathrm{~mm})$ & 3.528 \\
\hline Ethanol density $\rho_{\text {liq }}\left(\mathrm{kg} / \mathrm{m}^{3}\right)$ & 795 \\
\hline Ethanol surface tension, $\sigma(\mathrm{N} / \mathrm{m})$ & 0.0219 \\
\hline Gravity, $g\left(\mathrm{~m} / \mathrm{s}^{2}\right)$ & 9.81 \\
\hline Inner diameter of droplet dispenser, $\varnothing(\mathrm{mm})$ & 3.0 \\
\hline Boiling point $\left({ }^{\circ} \mathrm{C}\right)$ & 78 \\
\hline
\end{tabular}

\section{RESULT AND DISCUSSIONS}

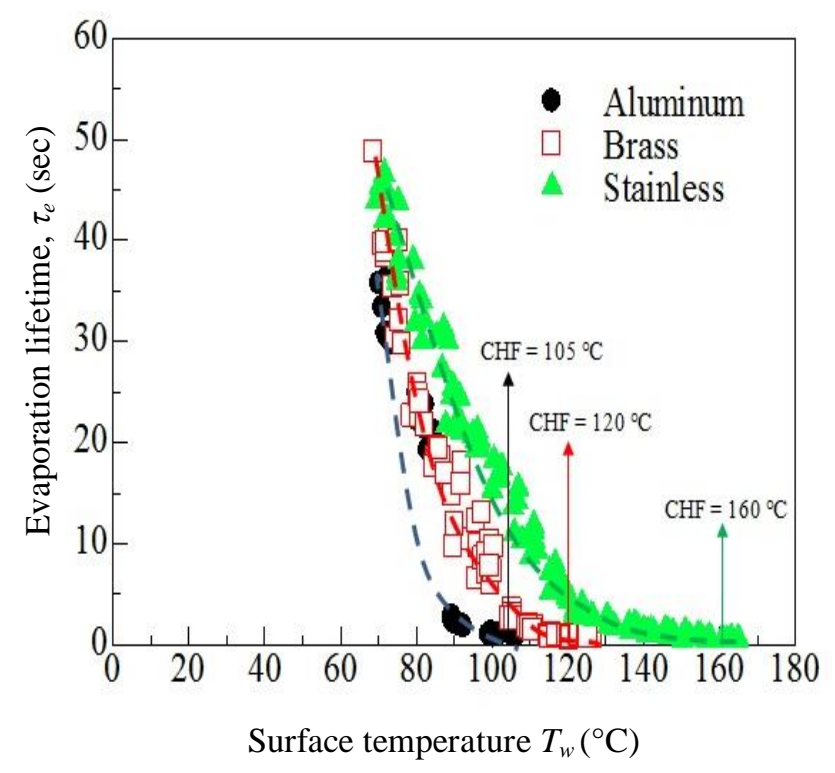

Figure 2: Relationship between surface temperature and evaporation lifetime for three (3) different types of material

Figure 2 shows the relationship between surface temperature and evaporation lifetime of droplet during impact onto a hot surface for three (3) different types of material. The black circle, red box and green pyramid represent the aluminum, brass and stainless steel materials used in the experiment. From Fig. 2, it was observed that the evaporation lifetime for every material shows a decreasing pattern. It was also observed that CHF for aluminum, brass and stainless starts at the surface temperatures of 105,120 and $160^{\circ} \mathrm{C}$, respectively. For aluminum, the evaporation lifetime was about $1.09 \mathrm{sec}$ at the surface temperature of $105{ }^{\circ} \mathrm{C}$. Meanwhile, the evaporation lifetimes during $\mathrm{CHF}$ for brass $\left(120^{\circ} \mathrm{C}\right)$ and 
N. A. Rosman et al., International Journal of Emerging Trends in Engineering Research, 8(5), May 2020, 1663 - 1666

stainless steel $\left(160{ }^{\circ} \mathrm{C}\right)$ were about 0.71 and $0.63 \mathrm{sec}$, respectively. During CHF, all materials showed an evaporation lifetime near $1 \mathrm{sec}$ order which is similar with other literatures. Although the evaporation curve shows a similar decreasing pattern for all materials, the evaporation lifetime recorded was quite different. For instance, at the surface temperature of $100{ }^{\circ} \mathrm{C}$, the evaporation lifetime for aluminum, brass and stainless were about $0.85,7.3$ and 15.34 sec, respectively. It showed that an evaporation lifetime during liquid-solid contact on stainless steel was much higher compared to other materials. From Fig. 2, it can be concluded that the CHF temperature for stainless steel is the highest among all materials. Furthermore, it can be concluded that material with low thermal inertia, $\beta$ will have much higher CHF. The details of the values of thermal properties are shown in Table 2 for reference.

Table 2: Properties for materials [27]

\begin{tabular}{l|l}
\hline \multicolumn{2}{c}{ Aluminum $(\mathrm{Al})$ properties at $300 \mathrm{~K}$} \\
\hline Density, $\rho\left(\mathrm{kg} / \mathrm{m}^{3}\right)$ & 2702 \\
\hline Specific heat, $C_{p}(\mathrm{~J} / \mathrm{kg} \cdot \mathrm{K})$ & 903 \\
\hline Heat conductivity, $k(\mathrm{~W} / \mathrm{m} \cdot \mathrm{K})$ & 237 \\
\hline \multicolumn{2}{c}{ Brass $(\mathrm{Br})$ properties at $300 \mathrm{~K}$} \\
\hline Density, $\rho\left(\mathrm{kg} / \mathrm{m}^{3}\right)$ & 8530 \\
\hline Specific heat, $C_{p}(\mathrm{~J} / \mathrm{kg} \cdot \mathrm{K})$ & 396 \\
\hline Heat conductivity, $k(\mathrm{~W} / \mathrm{m} \cdot \mathrm{K})$ & 121 \\
\hline \multicolumn{2}{c}{ Stainless steel $(\mathrm{St})$ properties at $300 \mathrm{~K}$} \\
\hline Density, $\rho\left(\mathrm{kg} / \mathrm{m}^{3}\right)$ & 7900 \\
\hline Specific heat, $C_{p}(\mathrm{~J} / \mathrm{kg} \cdot \mathrm{K})$ & 477 \\
\hline Heat conductivity, $k(\mathrm{~W} / \mathrm{m} \cdot \mathrm{K})$ & 14.90 \\
\hline
\end{tabular}

Table 2 shows the properties for three (3) different types of materials at $300 \mathrm{~K}$. The thermal inertia or thermal property $\beta=\sqrt{\rho C_{p} k}$ is an important parameter related to the interfacial temperature at the moment of contact between two bodies of different temperatures $\left(\rho, C_{p}\right.$ and $k$, represents the density, specific heat, and heat conductivity, respectively) [28].

\section{CONCLUSION}

The experimental work has been conducted to investigate the Critical Heat Flux (CHF) during impact of an ethanol droplet on a heated surface. Aluminum, brass and stainless steel (304) have been used in the experimental work. Our major interest is the evaporation lifetime of the droplet during impact onto a hot surface. We also investigated the relationship between the $\mathrm{CHF}$ and thermal inertia, $\beta$. From the experimental work, several conclusions can be made based on the data analysed.

(1) The Critical heat flux temperature for stainless steel is the highest among all the material $\left(160{ }^{\circ} \mathrm{C}\right)$.

(2) The CHF for aluminum and brass are about 105 and 120 ${ }^{\circ} \mathrm{C}$, respectively.

(3) Materials which have low thermal properties, $\beta$ are believed to have high Critical Heat Fluxes.
(4) The evaporation lifetime for all materials is nearly below 1 second order.

\section{ACKNOWLEDGEMENT}

The author would like to thank the Ministry of Education Malaysia and the Research Management and Innovation Centre of Universiti Malaysia Perlis (UniMAP) (project number FRGS/1/2018/TK03/UNIMAP/02/11) for awarding a research grant to undertake this project.

\section{REFERENCES}

1. Zhang, Chi, Li Zhang, and Hong Xu. The influence of surface orientation on the onset of nucleate boiling from microporous surfaces. International Journal of Heat and Fluid Flow 73 163-173 (2018). https://doi.org/10.1016/j.ijheatfluidflow.2018.05.010

2. Qi, Baojin, Ya Wang, Jinjia Wei, Yonghai Zhang, and Ting Yu. Nucleate boiling heat transfer model based on fractal distribution of bubble sizes. International Journal of Heat and Mass Transfer 128 1175-1183 (2019).

3. Li, Jia-Qi, Jia-Yi Zhang, Lin-Wei Mou, Yu-Hong Zhang, and $\mathrm{Li}-\mathrm{Wu}$ Fan. Enhanced transitional heat flux by wicking during transition boiling on microporous hydrophilic and superhydrophilic surfaces. International Journal of Heat and Mass Transfer 141 835-844 (2019). https://doi.org/10.1016/j.ijheatmasstransfer.2019.07.02 0

4. Ahmed, A. B., and M. S. Hamed. Modeling of transition boiling under an impinging water jet. International Journal of Heat and Mass Transfer 91 1273-1282 (2015).

5. Ni, Peiwei, Zhi Wen, Fuyong Su, Jie Huang, Xunliang Liu, Guofeng Lou, and Ruifeng Dou. Film boiling collapse in a solid hot sphere immersed in subcooled forced convection. Applied Thermal Engineering 166 114630 (2020). https://doi.org/10.1016/j.applthermaleng.2019.114630

6. Aursand, Eskil. Inclination dependence of planar film boiling stability. International Journal of Multiphase Flow 106 243-253 (2018).

7. Phan, Thanh-Hoang, Cong-Tu Ha, and Warn-Gyu Park. Numerical simulation of bubble collapse between two parallel walls and saturated film boiling on a sphere. International Journal of Heat and Mass Transfer 127 116-125 (2018).

8. Li, Guoli, Jinping Liu, Xiongwen Xu, Xingbin Lu, and Jianxun Chen. Contact angle measurements in the refrigerant falling film evaporation process. International Journal of Refrigeration 112 262-269 (2020). https://doi.org/10.1016/j.ijrefrig.2019.12.017 
N. A. Rosman et al., International Journal of Emerging Trends in Engineering Research, 8(5), May 2020, 1663 - 1666

9. Chauveau, Christian, Madjid Birouk, Fabien Halter, and Iskender Gökalp. An analysis of the droplet support fiber effect on the evaporation process. International Journal of Heat and Mass Transfer 128 885-891 (2019).

10. Chantasiriwan, Somchart. Online determination of heat transfer coefficients in sugar juice evaporation process. Journal of Food Engineering 230 (2018): 63-71 (2018).

11. Triantafyllidis, D., L. Li, and F. H. Stott. The effects of laser-induced modification of surface roughness of Al203-based ceramics on fluid contact angle. Materials Science and Engineering: A 390, no. 1-2 271-277 (2015).

https://doi.org/10.1016/j.msea.2004.08.016

12. Li, Dashu, Duo Zhang, and Zhiwei Zheng. Numerical analysis of hollow droplet impacts on a dry flat surface. International Journal of Heat and Mass Transfer 129 753-763 (2019).

13. Zhang, Guangxue, Lili Zhang, Jie Wang, and Eric Hu. Improving acoustic agglomeration efficiency by addition of sprayed liquid droplets. Powder Technology 317 181-188 (2017).

14. Fujimoto, Hitoshi, Shogo Sakane, Takayuki Hama, and Hirohiko Takuda. Transient contact behavior of aqueous polymer solution droplets with transparent hot solid. Experimental Thermal and Fluid Science 96 1-10 (2018).

15. Zhao, Peng, Graham K. Hargrave, Hendrik K. Versteeg, Colin P. Garner, Benjamin A. Reid, E. J. Long, and Huayong Zhao. The dynamics of droplet impact on a heated porous surface. Chemical Engineering Science 190 232-247 (2018). https://doi.org/10.1016/j.ces.2018.06.030

16. Illias, Suhaimi, Mohamad Shaiful Ashrul Ishak, Suhaila Hussain, and Khairul Azwan Ismail. High speed visualization and analysis of maximum spreading of water droplet during impact on hot horizontal surface. International Journal of Applied Engineering Research 11, no. 22 10832-10837 (2016).

17. Illias, S., M. A. Idris, and M. Z. M. Zain. Experimental Studies of Film Boiling Phenomena on Carbon Heated Surface. International Review of Mechanical Engineering 5, no. 5 812-817 (2011).

18. Illias, Suhaimi, Mohammad Nasim Hasan, Yuichi Mitsutake, and Masanori Monde. High speed observation and measurement of surface temperature and surface heat flux during impact of a droplet on hot surface. In International Heat Transfer Conference 15 Digital Library. Begel House Inc., (2014).

19. Illias, S., M. A. Idris, and M. Z. M. Zain. The Concept and Application of Miniaturization Boiling in Reactor Cooling System. International Review of Mechanical Engineering 5, no. 4 754-759 (2011).

20. Illias, S., N. A. Rosman, N. S. Abdullah, S. Hussain, M. E. Baharudin, M. A. Idris, and K. A. Ismail. Critical heat flux and Leidenfrost temperature on hemispherical stainless steel surface. Case Studies in Thermal Engineering 14100501 (2019).

https://doi.org/10.1016/j.csite.2019.100501

21. Illias, S., S. Hussain, N. A. Rosman, N. S. Abdullah, A. I. M. Shaiful, M. N. B. Omar, K. A. Ismail, and H. Ani. Evaporation lifetime and boiling curve on hemispherical stainless steel (304) surface. In $I O P$ Conference Series: Materials Science and Engineering, vol. 670, no. 1, p. 012013. IOP Publishing, (2019).

22. N. A. Rosman, S. Illias, S. Hussain, M. S. A. Ishak, M. N. Omar. Boiling curve and droplet evaporation lifetime on hot hemispherical copper surface. International Journal of Recent Technology and Engineering 8 (4) 8589-8592 (2019).

23. Mitsutake, Yuichi, Suhaimi Illias, Koutarou Tsubaki, Mohammad Nasim Hasan, and Masanori Monde. Measurement and Observation of Elementary Transition Boiling Process after Sudden Contact of Liquid with Hot Surface. Procedia Engineering 105 5-21 (2015). https://doi.org/10.1016/j.proeng.2015.05.002

24. Tsuboyama, Shinya, Tomofumi Higashi, Yuichi Mitsutake, bin S. Illias, Aloke Kumar Mazumder, Koutaro Tsubaki, and Masanori Monde. Characteristics of transient heat transfer and wetting phenomena during laminar jet quenching on rotating cylinder. Procedia Engineering 105 787-797 (2015).

25. Hasan, Mohammad Nasim, Ashik Hasan, Suhaimi Ilias, Yuichi Mitsutake, and Masanori Monde. Homogeneous Boiling Explosion Condition: From an Energy Point of View. Procedia Engineering 90 618-623 (2014).

26. Hasan, Mohammad Nasim, Ashik Hasan, Suhaimi Ilias, Yuichi Mitsutake, and Masanori Monde. Characteristics of Homogeneous Nucleation Boiling in Ethanol during Rapid Linear Boundary Heating. Procedia Engineering 90 624-630 (2014). https://doi.org/10.1016/j.proeng.2014.11.782

27. Y. A. Cengel and A. J. Ghajar. Heat and Mass Transfer, Fundamentals and Applications, $5^{\text {th }}$ Edition in SI Units, McGrawHill (2015).

28. Inada, Shigeaki, H. Sumiya, K. Shinagawa, and S. Illias. Mechanism Elucidation for the Miniaturization Boiling Phenomena in Droplet Collision Boiling System. In International Heat Transfer Conference 13. Begel House Inc., (2006). https://doi.org/10.1615/IHTC13.p28.460 